\title{
Automotive Rubber Product Design Using Response Surface Method
}

\author{
Dávid Huri1 ${ }^{12 *}$, Tamás Mankovits² \\ 1 Doctoral School of Informatics, University of Debrecen, H-4028 Debrecen, Kassai u. 26., Hungary \\ 2 Department of Mechanical Engineering, Faculty of Engineering, University of Debrecen, H-4028 Debrecen, Ótemető u. 2-4., \\ Hungary \\ *Corresponding author, e-mail: huri.david@eng.unideb.hu
}

Received: 20 April 2020, Accepted: 24 May 2020, Published online: 14 September 2021

\begin{abstract}
In rubber bumper design one of the most important technical properties of the product is the force-displacement curve under a compression load, which is a highly nonlinear behavior because of the large deformation, the rubber material and the contacts. Finite element analysis is a good way to evaluate the working characteristics of the rubber part. Fulfillment of customer needs requires a general iterative design method where the objective can be reached with the modification of the product shape. The determination of the optimum requires numerous iterations of finite element analysis which is computationally expensive. With the integration of the Response Surface Method (RSM) into the design process of a two-variable shape optimization task, the optimal design can be achieved more efficiently. Four different Design of Experiments (DOE) methods were used to intelligently chose design points. As a metamodeling technique, Genetic Aggregation was selected to predict the relation between the sampled geometric variables and the nonlinear objective function value. The Nonlinear Programming by Quadratic Lagrangian (NLPQL) and the Mixed-Integer Sequential Quadratic Programming (MISQP) algorithms with different settings were tested to find the optimum of the response surface. As a result, the most accurate and efficient DOE method and optimization algorithm were determined. The introduced Response Surface Method-based optimization is proved to be suitable to determine the shape of the rubber jounce bumper, which meets the technical requirements.
\end{abstract}

\section{Keywords}

rubber bumper, finite element method, shape optimization, Response Surface Method (RSM), Design of Experiments (DOE)

\section{Introduction}

Rubber bumpers built into air spring structures perform several critical tasks, such as working together with the air spring as a secondary spring, thus modifying the original characteristics of the air spring when pressed together. Consequently, designing their shape requires considerable effort. In the product design and development cycle, engineers are faced with several predefined requirements whose fulfillment is a difficult, time consuming and challenging task. The product investigated is applied in the air springs of lorries, where the force-displacement characteristic for the compression load is one of the most challenging technical requirements. In several cases, this is enforced by customer requirements, which leads to the iterative design process. Design engineers manage to achieve the required working characteristics by modifying the shape of the product. This process is termed shape optimization the simplest solution of which is to determine the optimal geometry through a series of trials with a study called "what if" based on design engineers' experiences. Owing to the continuum mechanics background and hyperelastic material model available, trials can be carried out by applying finite element analysis. If there is an opportunity to parameterize the process from creating a geometry to obtaining the results, conversion meeting technical requirements can be automated. In this case, numerous design optimization techniques can be used, which shortens design time and reduces engineering work.

Metamodels used for replacing engineering tasks requiring costly simulations are called Surrogate models (Forrester et al., 2008). Some papers could be found where metamodel-based design optimization was used for rubber product design. The finite element model of the bushing 
was used to simulate about 200 different combinations of parameters for four different material models. These simulations were used to calibrate the parameters of a series of interpolating functions (Previati et al., 2011). The orthogonal experiment table was adopted to design the geometric parameters of the samples on which the rubber mount numerical analyses were run. The finite element analysis results were used as samples to train the error backpropagation neural network model which defines the nonlinear global mapping relationship between the geometric parameters of the rubber mount and its primary stiffness in the three principal directions (Li et al., 2008). Shape optimization task of rubber bumpers was investigated, where learning points were analysed with finite element simulation. The SVR model was used to determine the given values of the objective functions of further constructions. Through screening search algorithm the optimal shape was determined (Mankovits et al., 2014).

The Response Surface Methodology (RSM) is an integration of statistical and mathematical techniques (Box and Wilson, 1951). This method explores the relation between the independent variables (input variables) and one or more dependent variables (response variables). The main idea of RSM is to use the Design of Experiments (DOE) statistical technique to obtain an optimal response (Myers et al., 2016). The aim DOE is to determine how many and what kind of experiments have to be carried out optimally to be able to obtain as much information as possible at the lowest cost, most precisely related to the effects of planning variables about the subject of the experiment that is the objective function (Erdősné Sélley et al., 2012). Several experiment designs exist based on statistical criteria, such as the general full or fractional factorial design, Central Composite Design, the random and Latin Hypercube Design, Box-Behnken Design, Taguchi design and several other procedures (Montgomery, 2017). Central Composite Design (CCD) for fitting second-order polynomial model was introduced by Box and Wilson (1951). The BoxBehnken three-level experimental design was used to generate a second-order response surface and required fewer runs than the CCD (Box and Behnken, 1960). RSM with CCD sampling was used for rocket engine nozzle optimization and the highly nonlinear objective function of the two-dimensional task was predicted successfully (Jéger and Veress, 2019). Morris and Mitchel (1995) introduced the selection of a Latin Hypercube Design (LHD) that maximizes the minimum distance among the points and was named as Maximin LHD. This space-filling design method is suitable for computer simulations. Furthermore, there are other space-filling experimental techniques (Joseph, 2016).

Optimization methods can be divided into local and global optimum search procedures. The Nonlinear Programming by Quadratic Lagrangian (NLPQL) algorithm applies a quasi-Newton technique and line search method, where the Armijo condition is used to determine the step size (Schittkowski, 1986). The Mixed-Integer Sequential Quadratic Programming (MISQP) algorithm is suitable for optimizing continuous and discrete input variables (Exler and Schittkowski, 2007). The method approaches the objective function by constructing a quadratic approximation, which reselects the model function in every iteration and chooses the quasi-Newton method to find the minimum. The algorithm applies the BFGS method to approach the Hessian matrix. The NLPQL and MISQP methods locally optimize procedures requiring gradient calculation. The current article does not deal with the investigation of procedures searching for the global optimum.

The paper introduces the considerations which are necessary for the finite element analysis of axisymmetric rubber products. Furthermore, the task of two-variable shape optimization of a rubber bumper is presented where the objective function is determined from the results of the finite element analysis. For sampling, the Face-Centered CCD, the Inscribed CCD, Maximin LHD and Box-Behnken Design have been chosen. Genetic Aggregation metamodeling technique is selected to generate the response surface between the design variables and the objective function value for each set of experimental design. To optimize the response surface the NLPQL and MISQP local search algorithms of different adjustments were run. In contrast with the industrial tasks, the solution of the shape optimization task is well-known in advance, whereby the precision of optimal constructions determined by the different DOE can be tested. Thereby, the main aim of the article is to test local search algorithms based on RSM, to specify their calculation costs for shape optimization of axisymmetric rubber spare parts.

\section{Model and methods}

\subsection{Two-dimensional shape optimization problem}

The current investigation aims to achieve current working characteristics by changing the shape of the product. The geometry of the product tested can be seen in Fig. 1. Due to its manufacturing and operational requirements, the height of the product in the current task is $d_{3}=40 \mathrm{~mm}$, 
the draft angle of the side is $d_{4}=3^{\circ}$ which are considered as design parameters. Should $\boldsymbol{d}$ be the vector of geometric design variables it can have its value in design space

$\boldsymbol{d}=\left(d_{1} ; d_{2}\right)$, where $\left\{\begin{array}{l}90 \leq d_{1} \leq 130[\mathrm{~mm}] \\ 10 \leq d_{2} \leq 50[\mathrm{~mm}]\end{array}\right.$

and $d_{1}$ is the outer diameter, while $d_{2}$ is the internal one.

The current investigation aims to test the precision and efficiency of the Response Surface Method-based design optimization, so the optimal characteristics have been determined from the $\boldsymbol{d}_{\text {opt }}=(117 ; 28) \mathrm{mm}$ geometric shape known in advance. During optimization the geometric sizes of the initial construction are $\boldsymbol{d}_{\text {initial }}=(100 ; 40) \mathrm{mm}$.

Let $\boldsymbol{\Omega}$ be the set of $\boldsymbol{d}$ design variables' vector. Let the objective function be $f(\Omega): \mathbb{R}^{n} \rightarrow \mathbb{R}$, the function which forms real numbers from set $\Omega \in \mathbb{R}^{n}$ and the relation can be determined by utilizing the so-called "white box" model, the analytic solution of which is yet unknown (Lenzen and Waller, 2004). The mathematical models of material, geometric and boundary conditions are available whereby their relation can be calculated by numerical methods (Logan, 2016).

The objective function is described as the difference between the initial and optimal working characteristics in Fig. 2. We wish to decrease the value of objective function during optimization by changing $\boldsymbol{d}$. This means that the task of optimization is to find the minimum value of the objective function and determine vector $\boldsymbol{d}_{\text {opt }}$ describing the optimal shape

$f\left(\boldsymbol{d}_{\text {opt }}\right)=\min _{\boldsymbol{d} \in \Omega} f(\boldsymbol{d})$.

Furthermore, the geometric optimization constraint also has to be accounted for when choosing potential constructions

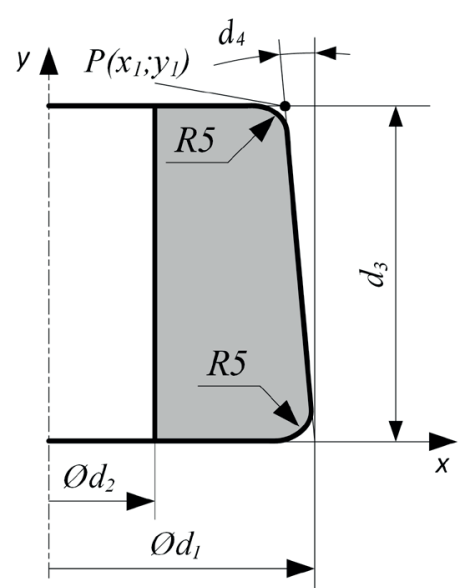

Fig. 1 The meridian section of the investigated rubber jounce bumper

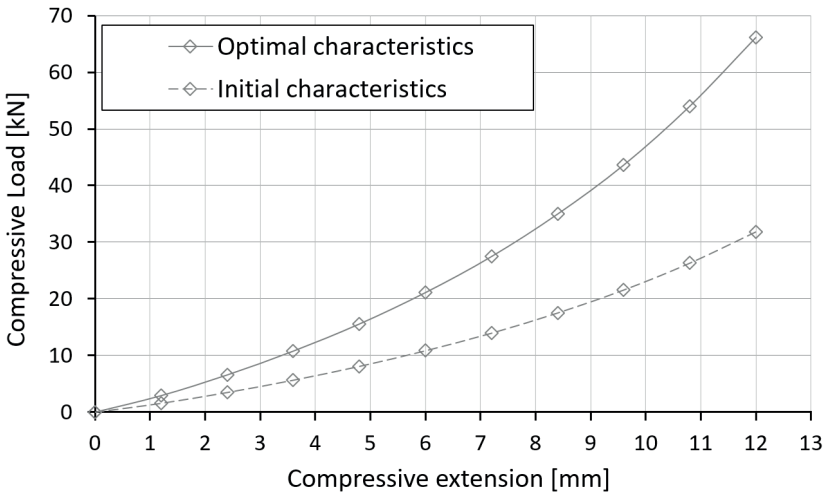

Fig. 2 The investigated rubber jounce bumper's working characteristics with the optimum and initial shape

$x_{1}-\frac{d_{2}}{2} \geq 15$ where $x_{1}=\frac{d_{3}}{\operatorname{tg}\left(90^{\circ}+d_{4}\right)}+\frac{d_{1}}{2}$

and $x_{1}$ is the coordinate of point $P$, as seen in Fig. 1.

\subsection{Finite element model of the rubber jounce}

The exact mixture of the Styrene-Butadiene Rubber (SBR) material of the investigated product is unknown. Measurements on the base material are needed to determine the material constants used for finite element analysis. The main load of the rubber jounce bumper is pressure, therefore compression test and curve-fitting process were performed by the Authors on rubber specimens. Two-term Mooney-Rivlin hyperelastic material model with $c_{10}=0.83485 \mathrm{MPa}, c_{01}=0.3971 \mathrm{MPa}$ and $\kappa=1000 \mathrm{MPa}$ material constants were selected for the finite element investigation of the rubber part. The goodness of the applied model was compared with laboratory measurement (Huri, 2016; Huri and Mankovits, 2018).

The geometry and boundary conditions of the investigated rubber specimen are axisymmetric, therefore axisymmetric linear quadrilateral elements were used for the meshing process. Simulation examines the relationship between force and deformation, which eliminate the need to create a fine mesh. The global element size was determined and applied in order to reduce the calculation time and to avoid the locking phenomena (Huri, 2017).

Under working conditions, the rubber jounce bumper comes into contact on the bottom and the top with flat steel plates, furthermore in case of large deformation self contact may happen between the bore's elements. Thus, frictional contact was defined, where the $\mu_{s}=0.6$ coefficient of static friction was selected according to (Cruz Gómez et al., 2013). The rigid top plate had a $12 \mathrm{~mm}$ prescribed displacement. Furthermore, the bottom curve nodes on the lower steel plate were constrained along the $y$-axis. 
The Finite Element Analysis (FEA) was solved in 100 equally distributed substeps and every $10^{\text {th }}$ substep was created as output. The operation of the constructed model and contacts can be observed through the deformation image in Fig. 3. The difference between the initial and optimal working characteristics can be determined by calculating the sum of squared differences in the given points of the two working characteristics

$$
f(\boldsymbol{d})=E(\boldsymbol{d})_{\mathrm{FEA}}=\sum_{i=10}^{100}\left(F_{i, \boldsymbol{d}_{\text {opt }}}-F_{i, \boldsymbol{d}}\right)^{2},
$$

where $i \in[10,20, \ldots 100], E(\boldsymbol{d})_{\mathrm{FEA}}$ is the error value in an investigated design point, $F_{i, d_{o p t}}$ is the optimal, while $F_{i, d}$ is the investigated working characteristics analyzed pressure force value in the $i^{\text {th }}$ substep. $F_{i, d}$ is determined by evaluating the reaction force on the steel plate. Table 1 contains the calculated objective function value for the initial shape $\boldsymbol{d}_{\text {initial }}(100,40) \mathrm{mm}$.

\subsection{Design of Experiments (DOE)}

In the next section, the precision of the surrogate model approaching the objective function to be applied largely depends on the number of design points and the distribution in the design area. If we approach the behavior of the response surface linearly it is enough to carry out a two-level experimental design, i.e. the number of different values in the case of the design variable. A threelevel sampling is needed with quadratic behavior whereas

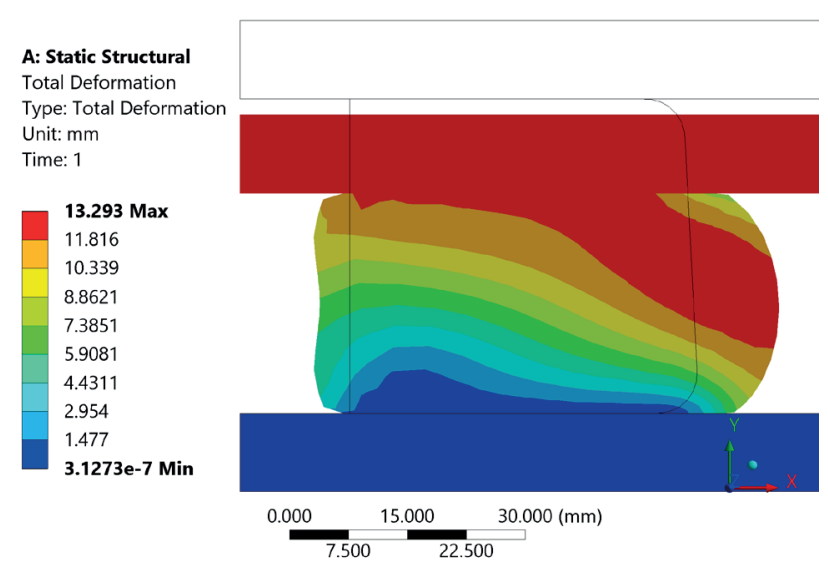

Fig. 3 Finite element model of the rubber jounce bumper and the obtained deformation state at $12 \mathrm{~mm}$ displacement load

Table 1 Calculated objective function value for different design

\begin{tabular}{lccc}
\multicolumn{4}{c}{ construction } \\
\hline $\begin{array}{c}d_{1} \\
{[\mathrm{~mm}]}\end{array}$ & $\begin{array}{c}d_{2} \\
{[\mathrm{~mm}]}\end{array}$ & $\begin{array}{c}E_{\mathrm{FEA}} \\
{[\mathrm{kN}]^{2}}\end{array}$ \\
\hline $\boldsymbol{d}_{\text {opt }}$ & 117 & 28 & 0 \\
$\boldsymbol{d}_{\text {initial }}$ & 100 & 40 & 3127.641 \\
\hline
\end{tabular}

the four-level one is necessary in case of cubic behavior. At least three-level sampling is needed due to the nonlinear property of rubber as well as the calculation method of the objective function required for the optimal task. The Box-Behnken Design is a three-level experiment out of the methods to be tested, as it samples five design points from the design area. The Central Composite Design with a Face-Centered option is a three-level experiment sampling nine design points following the full factorial design in case of two variables. The CCD with an Inscribed option is required for the same number but it is a five-level experiment as the former. With Optimal Space-Filling there is an opportunity to give an optional sampling number which has been determined to be nine in the current case. The experiment level is identical to the number of samples. There are several sampling methods available within this particular method, in the current case, the Maximin Latin Hypercube was selected. The design points sampled by the different experimental methods can be seen in Fig. 4.

With the use of the introduced finite element model of the rubber bumper, it is possible to calculate the $E(\boldsymbol{d})_{\mathrm{FEA}}$ values for each point of DOE design. To accelerate the finite element model pre- and post-processing the parameterization of these processes are necessary. Automation of the whole process is feasible with the use of Ansys DesignXplorer which allows us to directly access the geometry editor, finite element pre- and post-processor modules. Thereby the $f(\boldsymbol{d})$ objective function value was determined automatically for each sampling design, see Tables 2-5.

\subsection{Genetic aggregation response surface}

The current section aims to fit the surrogate model to continuously describe the relation between the design points and the objective functions for different sampling

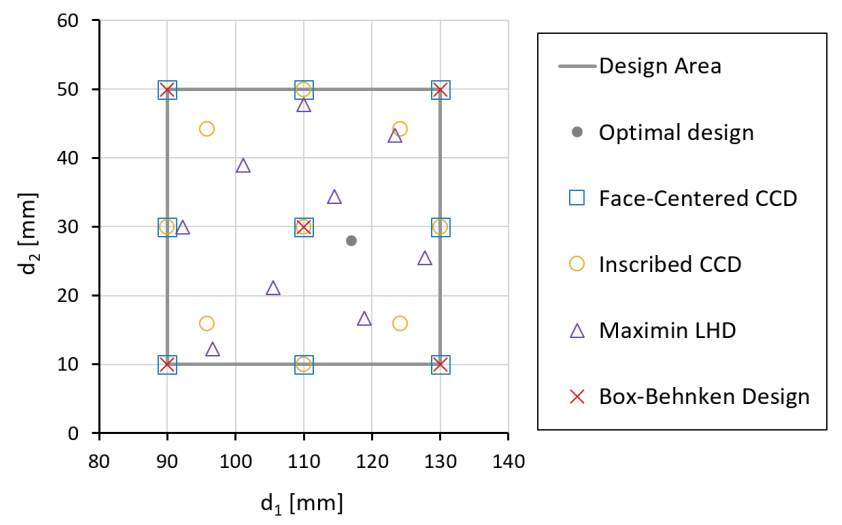

Fig. 4 The distribution of the sampling points in design space with different experimental methods 
Table 2 Design points sampled by the Face-Centered Central Composite Design, and their relevant objective function values

\begin{tabular}{lccc}
\hline Design Point & $\begin{array}{c}d_{1} \\
{[\mathrm{~mm}]}\end{array}$ & $\begin{array}{c}d_{2} \\
{[\mathrm{~mm}]}\end{array}$ & $\begin{array}{c}E(\boldsymbol{d})_{\mathrm{FEA}} \\
{[\mathrm{kN}]^{2}}\end{array}$ \\
\hline 1 & 110 & 30 & 535.75 \\
2 & 90 & 30 & 4228.41 \\
3 & 130 & 30 & 2000.31 \\
4 & 110 & 10 & 5.48 \\
5 & 110 & 50 & 2192.13 \\
6 & 90 & 10 & 2829.12 \\
7 & 130 & 10 & 6205.78 \\
8 & 90 & 50 & 6540.20 \\
9 & 130 & 50 & 22.23 \\
\hline
\end{tabular}

Table 3 Design points sampled by the Inscribed Central Composite Design, and their relevant objective function values

\begin{tabular}{lccc}
\hline Design Point & $\begin{array}{c}d_{1} \\
{[\mathrm{~mm}]}\end{array}$ & $\begin{array}{c}d_{2} \\
{[\mathrm{~mm}]}\end{array}$ & $\begin{array}{c}E(\boldsymbol{d})_{\mathrm{FEA}} \\
{[\mathrm{kN}]^{2}}\end{array}$ \\
\hline 1 & 110 & 30 & 535.75 \\
2 & 90 & 30 & 4228.41 \\
3 & 130 & 30 & 2000.31 \\
4 & 110 & 10 & 5.48 \\
5 & 110 & 50 & 2192.13 \\
6 & 95.86 & 15.86 & 1957.06 \\
7 & 124.14 & 15.86 & 2020.41 \\
8 & 95.86 & 44.14 & 4468.71 \\
9 & 124.14 & 44.14 & 11.84 \\
\hline
\end{tabular}

Table 4 Design points sampled by the Maximin Latin Hypercube Design, and their relevant objective function values

\begin{tabular}{lccc}
\hline Design Point & $\begin{array}{c}d_{1} \\
{[\mathrm{~mm}]}\end{array}$ & $\begin{array}{c}d_{2} \\
{[\mathrm{~mm}]}\end{array}$ & $\begin{array}{c}E(\boldsymbol{d})_{\mathrm{FEA}} \\
{[\mathrm{kN}]^{2}}\end{array}$ \\
\hline 1 & 118.89 & 16.67 & 512.99 \\
2 & 127.78 & 25.56 & 1969.12 \\
3 & 101.11 & 38.89 & 2803.70 \\
4 & 114.44 & 34.44 & 282.03 \\
5 & 96.67 & 12.22 & 1621.45 \\
6 & 105.56 & 21.11 & 631.62 \\
7 & 110.0 & 47.78 & 1975.07 \\
8 & 123.33 & 43.33 & 20.35 \\
9 & 92.22 & 30.00 & 3780.29 \\
\hline
\end{tabular}

Table 5 Design points sampled by the Box-Behnken Design, and their relevant objective function values

\begin{tabular}{lccc}
\hline Design Point & $\begin{array}{c}d_{1} \\
{[\mathrm{~mm}]}\end{array}$ & $\begin{array}{c}d_{2} \\
{[\mathrm{~mm}]}\end{array}$ & $\begin{array}{c}E(\boldsymbol{d})_{\mathrm{FEA}} \\
{[\mathrm{kN}]^{2}}\end{array}$ \\
\hline 1 & 110 & 30 & 535.75 \\
2 & 90 & 10 & 2829.12 \\
3 & 130 & 10 & 6205.78 \\
4 & 90 & 50 & 6540.20 \\
5 & 130 & 50 & 22.23 \\
\hline
\end{tabular}

methods. The response surface generated by the Genetic Aggregation algorithm is the weighted combination of one or several metamodels out of Full Second-Order Polynomials, Non-Parametric Regression, Kriging and Moving Least Squares

$f(\boldsymbol{d}) \approx \hat{y}_{\text {ens }}(x)=\sum_{i=1}^{N_{m}} w_{i} \hat{y}_{i}$,

where $\hat{y}_{\text {ens }}$ is the predicted value of total algorithms, $\hat{y}_{i}$ is the predicted value of the $i^{\text {th }}$ metamodel, $N_{m} \geq 1$ is the number of used metamodels, while $w_{i}$ is the weight of $i^{\text {th }}$ member in prediction (Acar, 2010; Viana et al., 2009; Wang et al., 2017). Further, the weight factor has to meet the following requirements

$\sum_{i=1}^{N_{m}} w_{i}=1$ and $w_{i} \geq 0,1 \leq i \leq N_{m}$.

The best combination can be chosen by running the genetic algorithm. So it can be pointed out that the emerging response surface is of identical precision with the metamodels applied in the genetic aggregation algorithm both in the best and the worst case.

\section{Results and discussion}

\subsection{Response surface fitted to the Face-Centered CCD}

There are several procedures available for the Central Composite Design for sampling. The current investigation was carried out with the Face-Centered option. The sampled points and the values of the objective function evaluated by the finite element method can be seen in Table 2, whereas the fitted response surface can be seen in Fig. 5 .

\subsection{Response surface fitted to the Inscribed CCD}

Inscribed Central Composite Design is suitable for sampling points located at an identical distance from the center of the design area. Unlike the face-centered type, it does not investigate the extreme values of the design area, while it is more suitable to identify quadratic effects. The sampled points and the values of the objective function evaluated by the finite element method can be seen in Table 3, whereas the fitted response surface can be seen in Fig. 6 .

\subsection{Response surface fitted to the Maximin LHD}

The number of sampling in the current investigation is identical with the number of design points sampled by CCD to be suitable for comparison. The extreme values of the design space were not examined but an evenly distributed sampling 


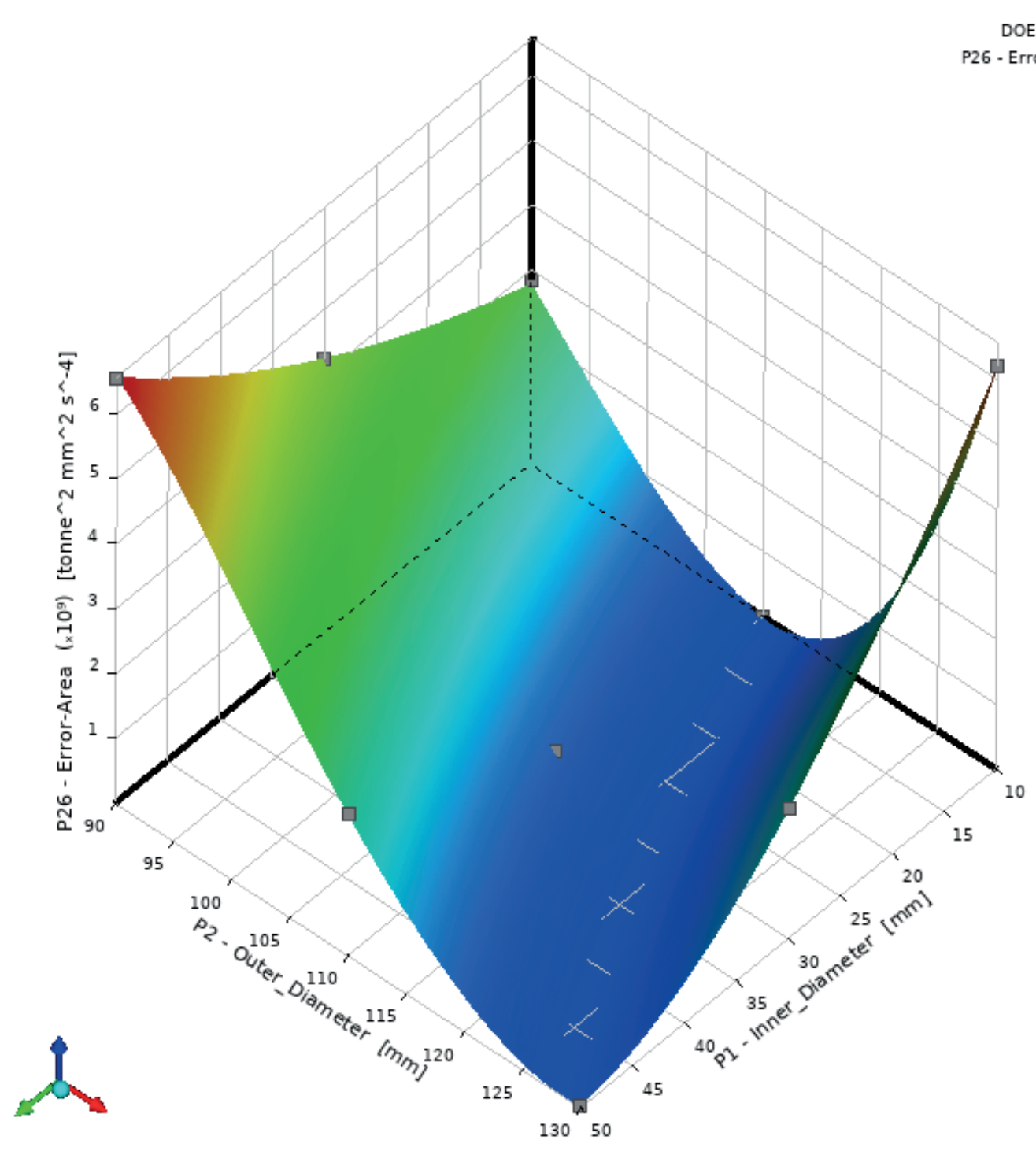

DOE Points

6 - Error-Area

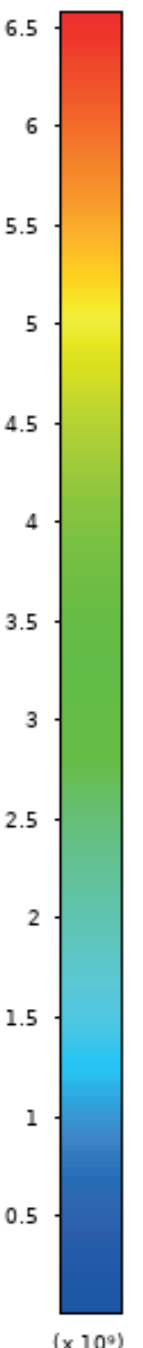

Fig. 5 Response surface fitted to the Face-Centered Central Composite Design experiment to predict the values of the objective function

was carried out by maximizing the minimal distances between the points. The nine-level experimental design can be ensured with the Latin Hypercube method. The sampled points and the values of the objective function evaluated by the finite element method can be seen in Table 4, whereas the fitted response surface can be seen in Fig. 7.

\subsection{Response surface fitted to the Box-Behnken Design}

Five points were sampled with the Box-Behnken Design, which differs from the Face-Centered CCD by not including the central value of variables' axis. The sampled points and the values of the objective function evaluated by the finite element method can be seen in Table 5, whereas the fitted response surface can be seen in Fig. 8. The response surface fitted to the Box-Behnken Design obviously differs from the three former surrogate models.

\subsection{Optimization of the response surface}

The main goal of the section is to find the minimum value of the surrogate model, where several algorithms are tested. The algorithms are compared in terms of precision and calculation costs. Starting point $\boldsymbol{d}_{\text {initial }}(100,40) \mathrm{mm}$ was selected to run NLPQL and MISQP algorithms. As in the tested task the analytic gradients needed to operate the algorithms were not available it had to be calculated numerically. The approach of the gradient can be carried out with a forward or central difference method (Olver, 2014). NLPQL P-I and MISQP P-I algorithms use the forward difference approximation, which samples one side of the design point to determine the gradient, while the NLPQL P-II and MISQP P-II algorithms use central difference. This method requires $50 \%$ more function calculation, as it samples both sides of the design point to 


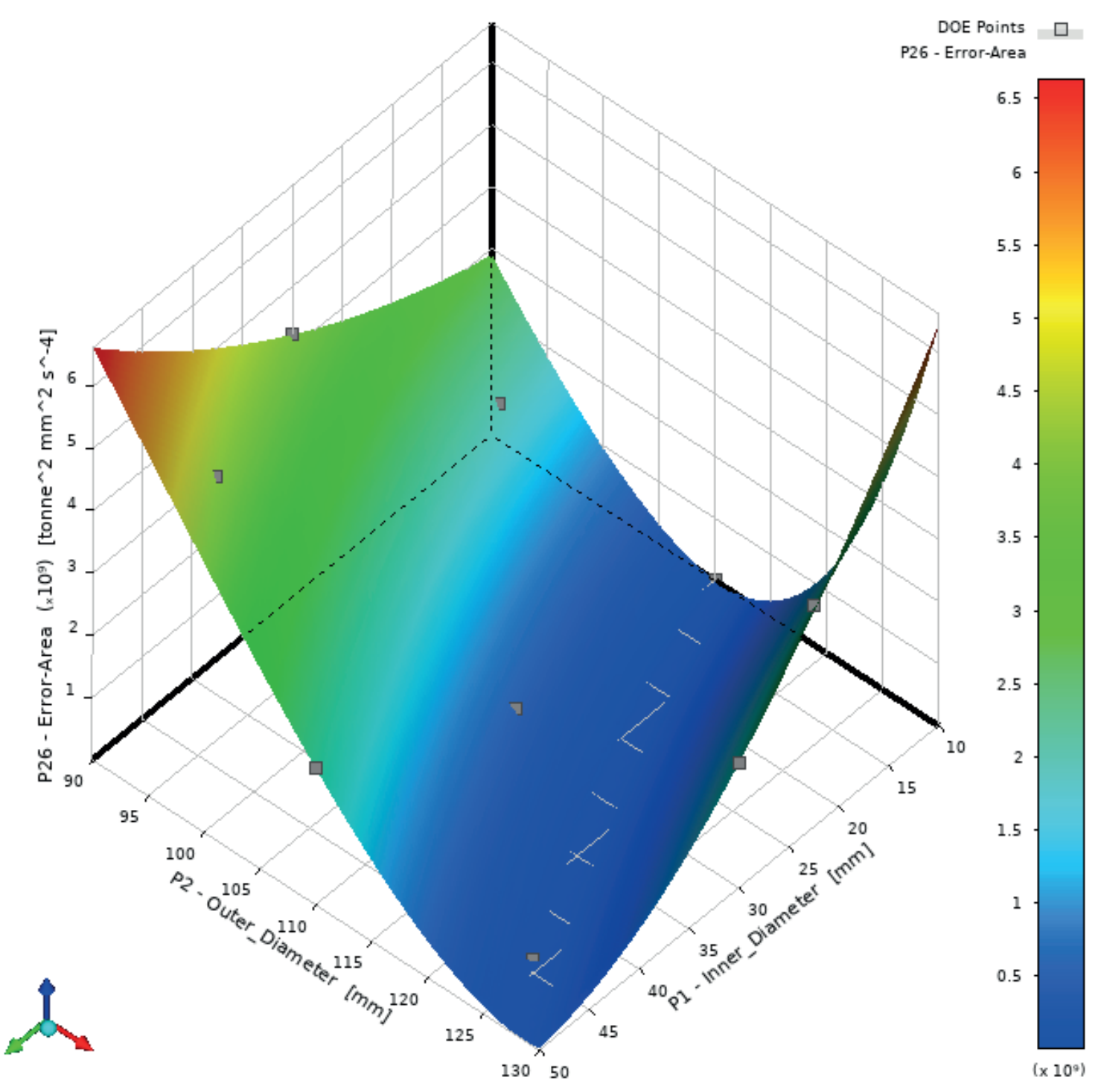

Fig. 6 Response surface fitted to the Inscribed Central Composite Design experiment to predict the values of the objective function

approximate the gradient. Table 6 contains the algorithms with different options.

The lowest value of the predicted objective function and its search method can be seen in Table 7. In terms of precision and the time required for the calculations, MISQP P-II algorithm using forward difference has proved the best. Information is provided about the precision of the surrogate model based shape optimization by the determined optimal values of the variables and the objective function value $E\left(\boldsymbol{d}_{\text {opt }}\right)_{\text {FEA }}$ defined with a finite element analysis. According to Fig. 9, neither method was suitable to find the known optimum variables' environment due to the difficulty of approximating the valley shaped objective function.

Objective function value zero belonging to the optimum was approached by all methods except the BoxBehnken experiment. The goodness of the solutions from a technical aspect has been proved by the working characteristics determined by finite element analysis, as it is demonstrated in Fig. 10.

\section{Conclusion}

Foremost the axisymmetric finite element model for the two-dimensional shape optimization of automotive rubber jounce bumper was built with the use of calibrated two-term Mooney-Rivlin material model. Sampling took place by means of Face-Centered CCD, Inscribed CCD, Maximin Latin Hypercube and Box-Behnken Design methods. As a metamodeling technique, Genetic Aggregation was selected which proved to be suitable to accurately predict the nonlinear objective function. To determine the optimum of response surfaces NLPQL and MISQP algorithms were run. In terms of precision and number of function runs 


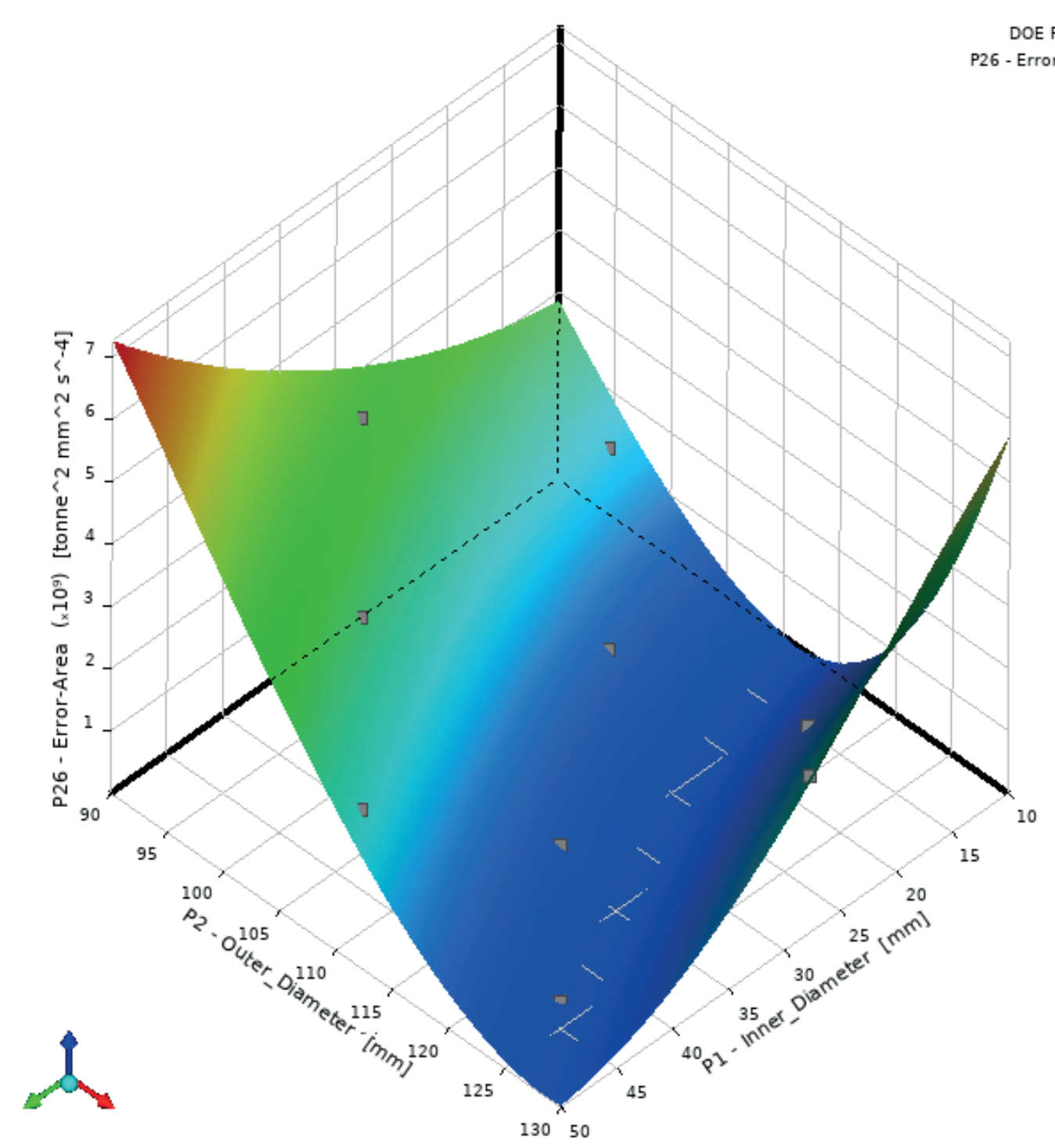

DOE Points $\square$

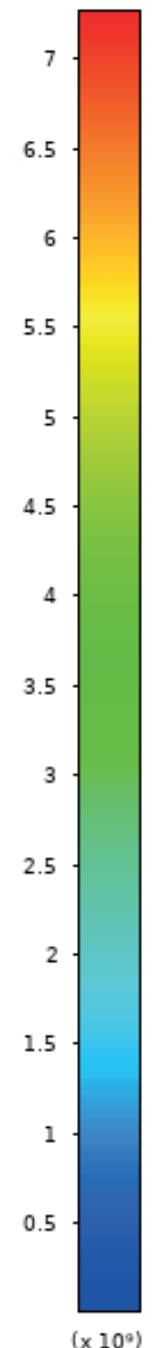

Fig. 7 Response surface fitted to the Maximin Latin Hypercube Design experiment to predict the values of the objective function

required for optimum determination, MISQP P-II adjusted algorithms proved the best. To approach the difference, choosing the forward difference calculation requiring less function running is the right choice as it did not influence precision. Based on the results neither method was suitable to find the known optimum variables' good environment due to the difficulty of approximating the valley shaped objective function. Based on the determined working characteristics, all procedures were good solutions from a technical point of view except for the Box-Behnken Design. Response surface prediction precision fitted to the Maximin Latin Hypercube sampling method equals the tested CCD methods with identical sampling. An advantage of the Optimal Space-Filling is that the number of sampling and thereby the prediction precision of the surrogate model can be further increased while accounting for the calculation cost of the optimization task. Therefore, the Maximin Latin Hypercube method is recommended for surrogate modeling of two-dimensional shape optimization task of rubber goods. The introduced response surface-based optimization method with the run of nine design points is proved to be suitable to determine the shape of the rubber jounce bumper which meets the technical requirements.

\section{Acknowledgement}

The research was financed by the Thematic Excellence Programme of the Ministry for Innovation and Technology in Hungary (ED_18-1-2019-0028), within the framework of the (Automotive Industry) thematic programme of the University of Debrecen. 


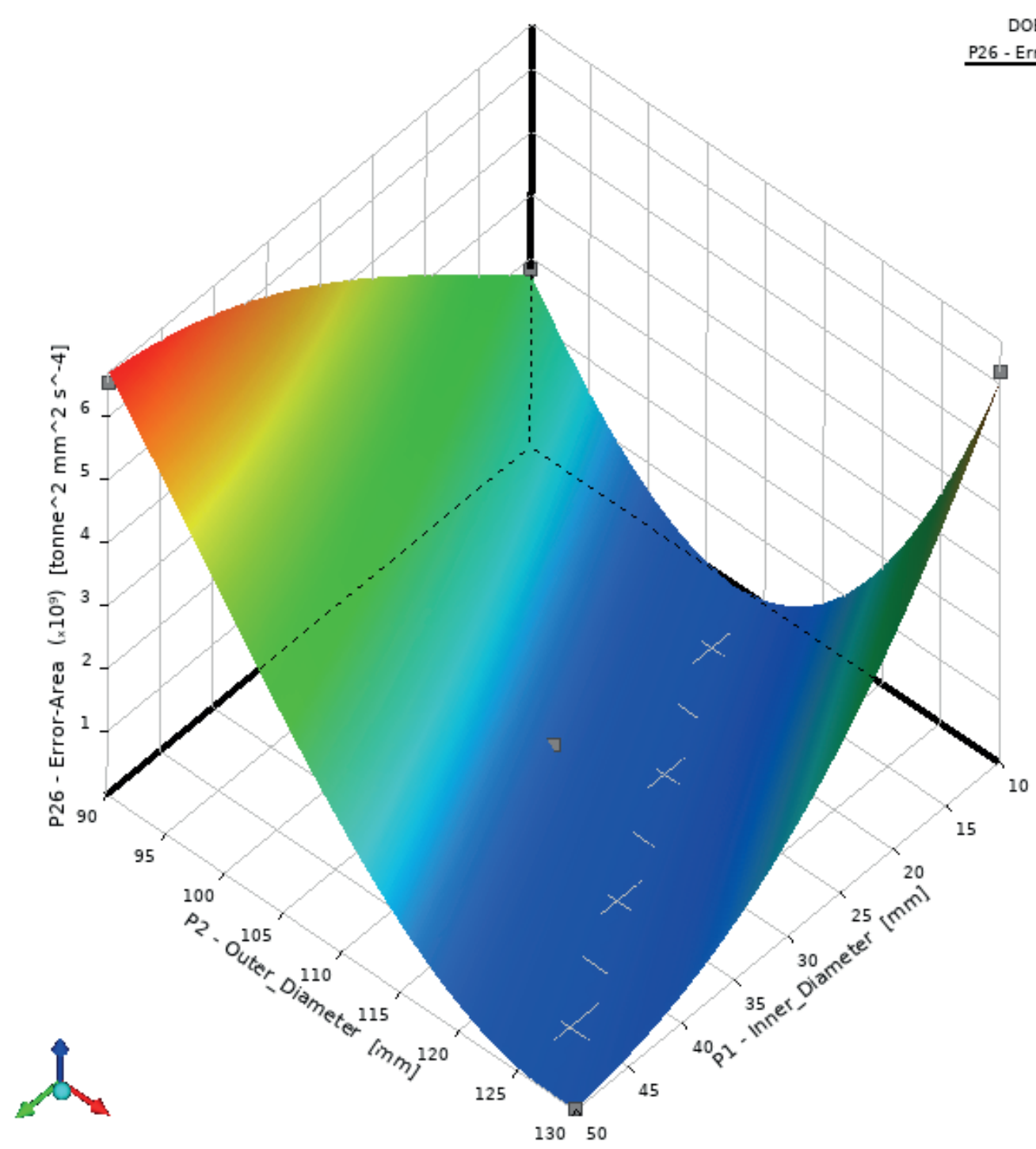

DOE Points

26 - Error-Area

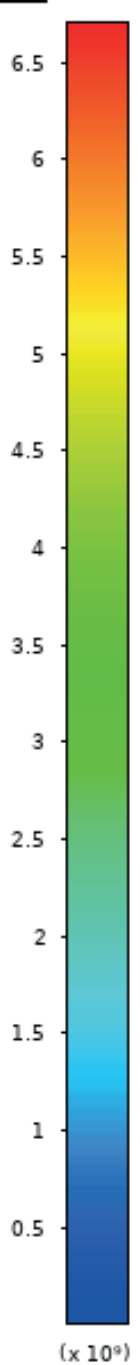

Fig. 8 Response surface fitted to the Box-Behnken Design experiment to predict the values of the objective function

Table 6 The options of local optimum search methods

\begin{tabular}{lccccc}
\hline & & NLPQL & & MISQP \\
& P-I & P-II & P-I & P-II \\
\hline finite difference approximation & Central & Forward & Central & Forward \\
\hline
\end{tabular}


Table 7 The minimum value of Response Surfaces (RS) and the search algorithm applied

\begin{tabular}{|c|c|c|c|c|c|c|}
\hline Design of Experiments & Algorithm & Number of evaluations & $\begin{array}{c}d_{1, \text { opt }} \\
{[\mathrm{mm}]}\end{array}$ & $\begin{array}{c}d_{2, o p t} \\
{[\mathrm{~mm}]}\end{array}$ & $\begin{array}{c}E\left(\boldsymbol{d}_{\text {opt }}\right)_{\mathrm{RS}} \\
{[\mathrm{kNN}]^{2}}\end{array}$ & $\begin{array}{c}E\left(\boldsymbol{d}_{\text {opt }}\right)_{\mathrm{FEA}} \\
{[\mathrm{kN}]^{2}}\end{array}$ \\
\hline \multirow{4}{*}{$\begin{array}{l}\text { Face Centered CCD } \\
\text { (9 Design Points) }\end{array}$} & NLPQL P-I & 32 & 116.88 & 27.6 & 1.1773 & \\
\hline & NLPQL P-II & 20 & 116.88 & 27.6 & 1.1772 & \\
\hline & MISQP P-I & 88 & 110.82 & 10.07 & 0.6786 & \\
\hline & MISQP P-II & 54 & 110.89 & 10.3 & 0.16745 & 0.13644 \\
\hline \multirow{4}{*}{$\begin{array}{l}\text { Inscribed CCD } \\
\text { (9 Design Points) }\end{array}$} & NLPQL P-I & 32 & 117.04 & 27.74 & 0.02547 & \\
\hline & NLPQL P-II & 20 & 117.04 & 27.74 & 0.02545 & \\
\hline & MISQP P-I & 27 & 115.61 & 24.37 & 0.01259 & \\
\hline & MISQP P-II & 17 & 115.61 & 24.36 & 0.01259 & 0.77545 \\
\hline \multirow{4}{*}{$\begin{array}{l}\text { Maximin LHD } \\
\text { (9 Design Points) }\end{array}$} & NLPQL P-I & 32 & 116.97 & 27.78 & 0.04252 & \\
\hline & NLPQL P-II & 20 & 116.97 & 27.78 & 0.04281 & \\
\hline & MISQP P-I & 27 & 115.56 & 24.38 & 0.00339 & \\
\hline & MISQP P-II & 17 & 115.56 & 24.38 & 0.00339 & 0.527529 \\
\hline \multirow{4}{*}{$\begin{array}{l}\text { Box-Behnken Design } \\
\text { (5 Design Points) }\end{array}$} & NLPQL P-I & 62 & 107.59 & 10.19 & 0.51104 & \\
\hline & NLPQL P-II & 38 & 107.61 & 10.21 & 0.51101 & 94.2689 \\
\hline & MISQP P-I & 61 & 107.5 & 10 & 0.51183 & \\
\hline & MISQP P-II & 38 & 107.5 & 10 & 0.51189 & \\
\hline Optimal design & - & - & 117 & 28 & - & 0 \\
\hline
\end{tabular}

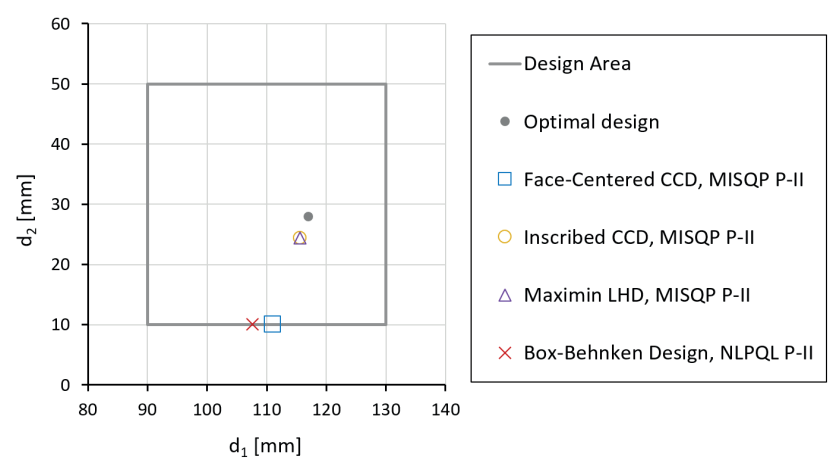

Fig. 9 Predicted optimum by the different RSM-based optimization methods

\section{References}

Acar, E. (2010) "Various approaches for constructing an ensemble of metamodels using local measures", Structural and Multidisciplinary Optimization, 42(6), pp. 879-896.

https://doi.org/10.1007/s00158-010-0520-z

Box, G. E. P., Behnken, D. W. (1960) "Some New Three Level Designs for the Study of Quantitative Variables", Technometrics, 2(4), pp. 455-475.

https://doi.org/10.2307/1266454

Box, G. E. P., Wilson, K. B. (1951) "On the Experimental Attainment of Optimum Conditions", Journal of the Royal Statistical Society. Series B (Methodological), 13(1), pp. 1-45. [online] Available at: http://www.jstor.org/stable/2983966 [Accessed: 17 April 2020]

Cruz Gómez, M. A., Gallardo-Hernández, E. A., Vite Torres, M., Peña Bautista, A. (2013) "Rubber steel friction in contaminated contacts", Wear, 302(1-2), pp. 1421-1425.

https://doi.org/10.1016/j.wear.2013.01.087

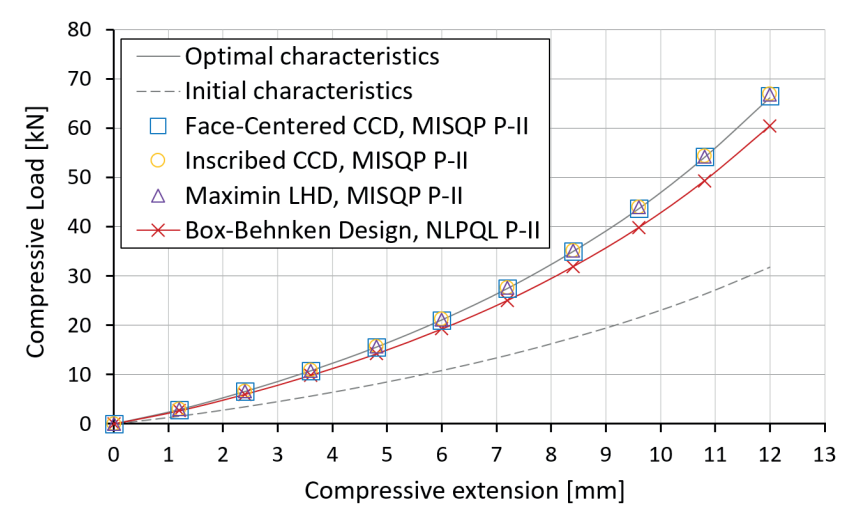

Fig. 10 Working characteristics defined by the different surrogate model-based optimization methods.

Erdősné Sélley, C., Gyurecz, G., Janik, J., Körtélyesi, G. (2012) "Mérnöki Optimalizáció" (Engineering Optimization), Typotex, Budapest, Hungary. (in Hungarian)

Exler, O., Schittkowski, K. (2007) "A trust region SQP algorithm for mixed-integer nonlinear programming", Optimization Letters, 1, pp. 269-280.

https://doi.org/10.1007/s11590-006-0026-1

Forrester, A. I. J., Sóbester, A., Keane, A. J. (2008) "Engineering Design via Surrogate Modelling: A Practical Guide", John Wiley \& Sons Ltd, Oxford, UK.

https://doi.org/10.1002/9780470770801

Huri, D. (2016) "Incompressibility and Mesh Sensitivity Analysis in Finite Element Simulation of Rubbers", International Review of Applied Sciences and Engineering, 7(1), pp. 7-12. https://doi.org/10.1556/1848.2016.7.1.2 
Huri, D. (2017) "Locking jelenség vizsgálata hiperelasztikus anyagok végeselem szimulációjában" (Locking Effect Analysis in Finite Element Simulation of Hyperelastic Materials), In: OGÉT 2017: XXV. Nemzetközi Gépészeti Konferencia, Cluj-Napoca, Romania, pp. 199-202. (in Hungarian)

Huri, D., Mankovits, T. (2018) "Comparison of the material models in rubber finite element analysis", IOP Conference Series: Materials Science and Engineering, 393, Article number: 012018. https://doi.org/10.1088/1757-899X/393/1/012018

Jéger, C., Veress, Á. (2019) "Novell Application of CFD for Rocket Engine Nozzle Optimization", Periodica Polytechnica Transportation Engineering, 47(2), pp. 131-135. https://doi.org/10.3311/PPtr.11490

Joseph, V. R. (2016) "Space-filling designs for computer experiments: A review", Quality Engineering, 28(Special Issue:1), pp. 28-35. https://doi.org/10.1080/08982112.2015.1100447

Lenzen, A., Waller, H. (2004) "From Black to White Box Models in Structural Mechanics", In: ICLODC $20042^{\text {nd }}$ International Conference Lifetime Oriented Design Concepts, Bochum, Germany, [online] Available at: https://www.researchgate.net/ publication/277133132 [Accessed: 11 April 2020]

Li, Q., Zhao, J., Zhao, B., Zhu, X. (2008) "Parameter Optimization of Rubber Mounts Based on Finite Element Analysis and Genetic Neural Network", Journal of Macromolecular Science, Part A, 46(2), pp. 186-192. https://doi.org/10.1080/10601320802594923

Logan, D. L., (2016) "A First Course in the Finite Element Method", Cengage Learning, Boston, MA, USA.

Mankovits, T., Szabó, T., Kocsis, I., Páczelt, I. (2014) "Optimization of the Shape of Axi-Symmetric Rubber Bumpers", Strojniški vestnik Journal of Mechanical Engineering, 60(1), pp. 61-71.

https://doi.org/10.5545/sv-jme.2013.1315
Montgomery, D. C. (2017) "Design and Analysis of Experiments", John Wiley \& Sons, Hoboken, NJ, USA.

Morris, M. D., Mitchell, T. J. (1995) "Exploratory designs for computational experiments", Journal of Statistical Planning and Inference, 43(3), pp. 381-402. https://doi.org/10.1016/0378-3758(94)00035-T

Myers, R. H., Montgomery, D. C., Anderson-Cook, C. M. (2016) "Design of Experiments for Fitting Response Surfaces", In: Response Surface Methodology: Process and Product Optimization Using Designed Experiments, John Wiley \& Sons, Hoboken, NJ, USA, pp. $369-449$

Olver, P. J. (2014) "Introduction to Partial Differential Equations", Springer International Publishing, Cham, Switzerland. https://doi.org/10.1007/978-3-319-02099-0

Previati, G., Kaliske, M., Gobbi, M., Mastinu, G. (2011) "Structural optimization of a rubber bushing for automotive suspension", In: Jerrams, S., Murphy, N. (eds.) Constitutive Models for Rubber VII, CRC Press, Abingdon, UK, pp. 307-312.

Schittkowski, K. (1986) "NLPQL: A fortran subroutine solving constrained nonlinear programming problems", Annals of Operations Research, 5(2), pp. 485-500. https://doi.org/10.1007/BF02022087

Viana, F. A. C., Haftka, R. T., Jr. Steffen, V. (2009) "Multiple surrogates: how cross-validation errors can help us to obtain the best predictor", Structural and Multidisciplinary Optimization, 39(4), pp. 439-457. https://doi.org/10.1007/s00158-008-0338-0

Wang, S., Jian, G., Xiao, J., Wen, J., Zhang, Z. (2017) "Optimization investigation on configuration parameters of spiral-wound heat exchanger using Genetic Aggregation response surface and MultiObjective Genetic Algorithm", Applied Thermal Engineering, 119, pp. 603-609.

https://oi.org/10.1016/j.applthermaleng.2017.03.100 